Article

\title{
The Associations of SCFA with Anthropometric Parameters and Carbohydrate Metabolism in Pregnant Women
}

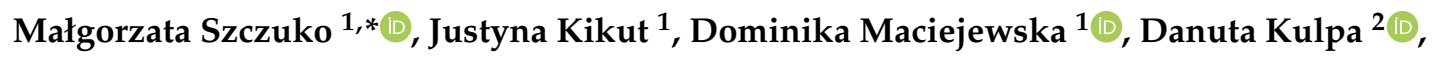 \\ Zbigniew Celewicz $^{3}$ and Maciej Ziętek ${ }^{3}$ \\ 1 Department of Human Nutrition and Metabolomics, Pomeranian Medical University in Szczecin, \\ Broniewskiego 24, 71-460 Szczecin, Poland; justyna.kikut@pum.edu.pl (J.K.); domi.maciejka@wp.pl (D.M.) \\ 2 Department of Genetics, Plant Breeding and Biotechnology, Faculty of Environmental Management and \\ Agriculture, West Pomeranian University of Technology, Słowackiego 17, 71-434 Szczecin, Poland; \\ danuta.kulpa@zut.edu.pl \\ 3 Department of Perinatology, Obstetrics and Gynecology, Pomeranian Medical University in Szczecin, \\ Siedlecka 2, 72-010 Police, Poland; sekr.perinat@spsk1.szn.pl (Z.C.); maciej.zietek@pum.edu.pl (M.Z.) \\ * Correspondence: malgorzata.szczuko@pum.edu.pl; Tel.: +48-91-441-4810; Fax: +48-91-441-4807
}

Received: 4 November 2020; Accepted: 30 November 2020; Published: 3 December 2020

\begin{abstract}
Short-chain fatty acids (SCFAs) mediate the transmission of signals between the microbiome and the immune system and are responsible for maintaining balance in the anti-inflammatory reaction. Pregnancy stages alter the gut microbiota community structure, which also synthesizes SCFAs. The study involved 90 pregnant women, divided into two groups: 48 overweight/obese pregnant women (OW) and 42 pregnant women with normal BMI (CG). The blood samples for glucose, insulin, and HBA1c were analyzed as well as stool samples for SCFA isolation (C2:0; C3:0; C4:0i; C4:0n; C5:0i; C5:0n; C6:0i; C6:0n) using gas chromatography. The SCFA profile in the analyzed groups differed significantly. A significant positive correlation between C2:0, C3:0, C4:0n and anthropometric measurements, and between C2:0, C3:0, C4:0n, and C5:0n and parameters of carbohydrate metabolism was found. SCFA levels fluctuate during pregnancy and the course of pregnancy and participate in the change in carbohydrate metabolism as well. The influence of C2:0 during pregnancy on anthropometric parameters was visible in both groups (normal weight and obese). Butyrate and propionate regulate glucose metabolism by stimulating the process of intestinal gluconeogenesis. The level of propionic acid decreases with the course of pregnancy, while its increase is characteristic of obese women, which is associated with many metabolic adaptations. Propionic and linear caproic acid levels can be an important critical point in maintaining lower anthropometric parameters during pregnancy.
\end{abstract}

Keywords: SCFA; pregnancy; propionic acid; butyric acid; caproic acid; heptanoic acid

\section{Introduction}

\subsection{SCFAs-Synthesis, Occurrence and Role}

Interest in dietary fiber, gut fermentation, and probiotics has led to studies on short chain fatty acids (SCFA), such as acetic, propionic, and n-butyric acids produced in the large intestine by gut bacteria. SCFA arouse interest in the context of issues related to the microbiota, which constitute the group of microorganisms including bacteria, archaea, viruses, and fungi living in our body. It can be estimated that over 1000 species of microorganisms reside in our intestines, the vast majority of which are bacteria $[1,2]$. Not only species diversity, but also the estimated number of around one hundred billion 
cells, represent a great potential influencing the health and disease status [1]. The gut microbiota can regulate about $10 \%$ of the host's transcriptome, i.e., genes involved in the immune response, proliferation, and metabolism, which is especially important in pregnant women [3]. The mentioned microbiota produce metabolites, including SCFAs, B vitamins, hydrochloride, 3-hydroxy-3-methylbutyric acid (HMB), trimethylamine (TMAO), and others, which significantly affect the balance and disturbance of the homeostasis of a human body [4]. Microbial metabolites or components may be related to diseases such as allergic and immune disorders (SCFAs, B vitamins), colorectal cancer (SCFAs, B vitamins, $\mathrm{N} 1, \mathrm{~N} 12$-diacetylspermine), bacterial vaginosis and other sexually transmitted infections (polyamines, HBP), hypertension and inflammation, preterm labour (SCFAs), cardiovascular diseases, obesity and metabolic syndrome (TMAO), and type 2 diabetes (TMAO) [4]. Clinical evidence confirms the influence of SCFAs not only on the functioning of the colon, but also the intestinal immune system and metabolic process efficiency $[2,5]$. SCFAs are produced by carbohydrate fermentation in the large intestine (colon) that have not been digested in the small intestine [6,7]. Branched SCFAs (BSCFAs), e.g., isobutyric and isovaleric acid, are generated by the fermentation of branched amino acids (valine, leucine, and isoleucine) generated from undigested protein reaching the colon. Acetic acid, propionic acid, and butyric acid can be produced by gut microbes generated from colonic fermentation of dietary fibers [8,9]. As result of non-digestible carbohydrate bacterial fermentation in the colon, butyrate may constitute a major energy source for epithelial cells and influence the intestinal epithelial barrier function with immune function modulation [2]. There is a strong relationship between the intestinal microflora, its metabolites (mainly SCFAs), and ingested food [10]. SCFAs include acetic acid (C2: 0), propionic acid (C3: 0), butyric acid (C4: 0), valeric acid (C5: 0), and caproic acid (C6: 0), of which butyrate, acetate, and propionate are the most common SCFAs in our body as they account for $\geq 95 \%$ of the total SCFA pool [10]. Up to 10\% of the daily caloric requirements is provided by SCFAs, which are used as a source of energy [10]. A small amount of C5: 0-C6: 0 acids may come from food such as herbs. The amount of SCFAs in the colon is maintained at the level of $60-150 \mathrm{mmol} / \mathrm{kg}$, and the ratios are 60:25:15 acetate, propionate, and butyrate, respectively [11]. Studies on fecal gut microbiota have shown that at a $\mathrm{pH}$ 5.5, butyrate-producing bacteria, such as Roseburia spp. and Faecalibacterium prausnitzii belonging to the Firmicutes type, account for $20 \%$ of the total bacterial count. In the distal part of the large intestine, bacteria producing C3:0 and C2:0 are dominant, while the production of C4:0 decreases [12].

The large intestine is inhabited mainly by anaerobic bacteria, e.g., bacteria of the genera Bacteroides spp., Bifidobacterium spp., lactobacilli, streptococci, and eubacteria [13]. Bacteroides are one of the major lineages of bacteria, whose abundance reaches up to $30 \%$ of the entire bacterial population. The increase in SCFA production through bacterial fermentation of microbiota causes a $\mathrm{pH}$ decrease [14]. Thus, the overgrowth of $\mathrm{pH}$-sensitive pathogenic bacteria may be prevented by lower $\mathrm{pH}$ values and raised SCFA [14]. The gut microbiota can be considered as a "metabolic organ" which, through the SCFA action, may influence many processes and play an important role in metabolic dysfunction during gestation [15]. The disruption of homeostasis contributes to a variety of metabolic disorders to which pregnant women are particularly exposed, due to the exceptional physiological state of gestation. It is estimated that about $60 \%$ of SCFAs diffuse into the lamina propria from the intestinal lumen through the intestinal epithelium, and about $5 \%$ of SCFAs are excreted in the faeces [10]. SCFAs are a source of energy for intestinal epithelial cells $[10,16-18]$. Colonocytes promote butyrate, which constitute the main energetic substrate [9]. This process takes place even in the presence of other substrates such as glucose or glutamine, meaning that colonocytes prefer butyrate. Butyrate provides about $70 \%$ of the energy requirements of the colon cells. It is an essential component for the development and differentiation of colonocytes [19]. Hormonal and immunological changes in pregnancy may strongly influence the formation of intestinal bacterial $[20,21]$. 


\subsection{The Role of SCFA in Pregnancy}

Pregnancy is a dynamic period during which physiological, anatomical, and metabolic changes occur $[22,23]$. Metabolic and immunological shifts may be compared to the metabolic syndrome [24,25].

At the beginning of pregnancy, an increase in insulin release from the pancreas is observed, with initially unchanged tissue sensitivity to its effects. Only in the late first-trimester and midpregnancy does the insulin sensitivity begin to decline and is finally reduced [26]. The last trimester of pregnancy is defined as a diabetogenic state, due to increased glucose levels in plasma of a pregnant woman [23]. The first two trimesters of pregnancy are a period of anabolic transformations with intense lipogenesis. In the third trimester, a catabolic phase is observed with increased lipolysis, and increased serum free fatty acids and VLDL lipoproteins. The diabetogenic effects of hormones such as 17 beta estradiol, progesterone, prolactin, placental lactogen and an increase in adipose tissue lead to pregnancy insulin resistance. However, glucose metabolism in pregnancy may also be regulated by the gut microbiota. It has been demonstrated that the abundance of the Actinobacteria genus Collinsella is positively correlated with circulating insulin [27]. The research data show that during pregnancy, as many as $70 \%$ of women demonstrate increased growth of inflammation-associated bacteria $[18,27]$. The growth of Firmicutes bacteria, including Faecalibacterium and Eubacterium, characterized by the production of C4:0, is observed. Proteobacteria and Actinobacteria overgrowth is also found to correlate with inflammatory bowel diseases and the level of pro-inflammatory cytokines $[15,28,29]$. It is suggested that features of the microbiota in early gestation may predict the pregnancy outcome [23]. Importantly, it has been shown that women who were overweight or obese before pregnancy (BMI $\geq 25)$ or in pregnancies complicated by gestational diabetes mellitus (GDM) had a reduced diversity of microorganisms [25]. There are data confirming that in nonpregnant hosts, the gut microbiota may also induce symptoms of metabolic syndrome [25]. The gut microbiota interacts with the host, altering the host physiological and metabolic processes. The gut microbiota plays a critical role in the development of obesity, insulin resistance, and type- 2 diabetes as well. In patients with chronically impaired blood glucose response, the risk for type-2 diabetes appearance rises to $70 \%$ [22].

Thus, the number of microorganisms with anti-inflammatory properties, which are important in the production of butyrate, e.g., Faecalibacterium, decreases during pregnancy, as well as in metabolic disorders. These changes are considered to play a key role in the development of insulin resistance (IR) and weight gain in pregnant women in the last trimester. In pregnancy, SCFAs may also regulate inflammatory processes involved in labor and modulate inflammatory pathways in fetal membranes [6].

The possibilities of changing the body's functions, both at the cellular and molecular level, are possible through G-coupled protein-coupled receptors 41 and 43 (GPR41 and GPR43), currently renamed for their function into free fatty acid receptors 2 and 3 (FFAR2 and FFAR3), and the histone deacetylase (HDAC) inhibitory mechanism. The FFAR2 receptor is activated mainly by acetate and propionate, while FFAR3 by the butyrate and propionate action $[8,28]$. The SCFA transporters in the organism are monocarboxylate transporter 1 (MCT-1) and sodium-coupled monocarboxylate transporter 1 (SMCT-1) [30]. The most important substrates for SCFA production are polysaccharides.

Summarizing the above, the content of SCFA depends on many factors, including diet, age, physiological state, genotype of the organism and, above all, the state of the intestinal microflora [14,29]. This work focuses on changes in the prevalence of microbiota metabolites, i.e., SCFAs, during pregnancy with an emphasis on its initial stage. The authors decided to determine whether and how SCFAs change during pregnancy as well as to analyze their importance for the metabolic parameters of carbohydrate metabolism, including body weight, BMI, and weight gain during pregnancy. This little-known but significant aspect will deepen the knowledge and create new possibilities for pregnant women and their offspring attending primary care clinics. 


\section{Results}

The average daily dietary nutrient intake within two days before stool sampling did not differ significantly between the analyzed groups (OW and CG), except for glucose levels. Trends of lower fructose and fiber consumption in the obese group were visible (Table 1).

Table 1. Average consumption of nutrients in the diet in both groups.

\begin{tabular}{cccc}
\hline & OW Avg \pm SD & CG Avg \pm SD & $p$-Value \\
\hline Protein $(\%)$ & $16.52 \pm 3.1$ & $14.72 \pm 2.81$ & 0.157 \\
\hline Vegetable $(\mathrm{g})$ & $29.37 \pm 5.79$ & $35.13 \pm 6.72$ & 0.301 \\
\hline Animal $(\mathrm{g})$ & $64.95 \pm 17.82$ & $68.49 \pm 15.61$ & 0.416 \\
\hline Fat $(\%)$ & $38.31 \pm 7.09$ & $39.27 \pm 7.96$ & 0.431 \\
\hline Cholesterol $(\mathrm{mg})$ & $221.52 \pm 104.23$ & $245.64 \pm 132.4$ & 0.184 \\
\hline Carbohydrates $(\%)$ & $43.23 \pm 8.29$ & $43.96 \pm 9.02$ & 0.649 \\
\hline Dietary fibre $(\mathrm{g})$ & $18.33 \pm 5.21$ & $21.41 \pm 7.37$ & $0.091 *$ \\
\hline Glucose & $64.86 \pm 15.62$ & $34.89 \pm 12.46$ & $\mathbf{0 . 0 4 4}$ \\
\hline Lactose & $13.85 \pm 4.62$ & $12.31 \pm 5.32$ & 0.693 \\
\hline Fructose & $12.71 \pm 5.29$ & $16.98 \pm 6.31$ & 0.083 * \\
\hline Saccharose & $62.65 \pm 12.47$ & $56.72 \pm 10.12$ & 0.316 \\
\hline Starch & $138.42 \pm 27.18$ & $162.76 \pm 32.84$ & 0.485 \\
\hline
\end{tabular}

The bold text-significant; ${ }^{*}$ — trend towards significance.

The SCFA profile in the OW group differed significantly from that in the CG, as shown in Table 2. Statistically significant higher levels were observed in relation to: C3: 0 (propionic acid), in the OW group and a reduced rate of C6: 0 (caproic acid) in the OW group in relation to the CG. There was also a decreased tendency of linear C5: 0 (valeric acid) in the OW group (Table 2).

Table 2. Comparison of the SCFAs in the stool in the analyzed study groups of women (OW and CG).

\begin{tabular}{ccccc}
\hline SCFAs (\%) & Total $(\boldsymbol{n}=\mathbf{9 0})$ & OW Avg \pm SD & CG Avg \pm SD & $p$-value \\
\hline C 2:0 acetic & $36.94 \pm 7.69$ & $36.93 \pm 9.22$ & $36.95 \pm 8.54$ & 0.991 \\
\hline C 3:0 propionic & $19.63 \pm 6.08$ & $20.17 \pm 6.80$ & $17.33 \pm 3.91$ & $\mathbf{0 . 0 2 2}$ \\
\hline C 4:0 i butyric (branched) & $5.38 \pm 3.44$ & $5.55 \pm 4.48$ & $5.22 \pm 1.80$ & 0.569 \\
\hline C 4:0 n butyric (linear) & $21.37 \pm 8.18$ & $21.28 \pm 8.23$ & $21.48 \pm 8.52$ & 0.915 \\
\hline C 5:0 i valeric (branched) & $8.32 \pm 4.02$ & $7.87 \pm 4.06$ & $8.86 \pm 3.93$ & 0.255 \\
\hline C 5:0 n valeric (linear) & $5.11 \pm 2.27$ & $4.62 \pm 1.86$ & $5.58 \pm 2.67$ & $0.055 *$ \\
\hline C 6:0 i caproic (branched) & $0.36 \pm 0.47$ & $0.41 \pm 0.61$ & $0.32 \pm 0.25$ & 0.384 \\
\hline C 6:0 n caproic (linear) & $1.90 \pm 1.74$ & $1.46 \pm 1.55$ & $2.30 \pm 1.8$ & $\mathbf{0 . 0 2 3}$ \\
\hline
\end{tabular}

The bold text-significant; ${ }^{*}$ - trend towards significance.

Analyzing the correlations of anthropometric parameters in all pregnant women, no significant relationship was demonstrated (Table 3). A significant positive correlation between C3:0 and the glucose level was observed at $0 \mathrm{~min}$ for OGTT and glycated hemoglobin (HbA1c). Moreover, correlations with biochemical measurements also showed negative correlations of C 4: $0 \mathrm{n}$ and C 6: $0 \mathrm{n}$ (linear) with the glucose level at $0 \mathrm{~min}$ with respect to the OGTT and insulin level as well (Table 3).

Because we assumed that the individual dependencies could mask each other, the next step was to determine the relationship between the anthropometric and biochemical parameters and the SCFA concentrations in the OW and CG groups (Tables 4 and 5). In the group of women who were overweight or obese before pregnancy, we found a positive correlation between C2:0 with nearly all anthropometric and biochemical parameters except the week of pregnancy, body weight gain, and glucose levels in the OGTT at $120 \mathrm{~min}$ (Table 4). C3: 0 was found to correlate positively with body 
weight gain during pregnancy, $\mathrm{HbA} 1$ levels and glucose levels in the OGTT at $0 \mathrm{~min}$. The remaining anthropometric parameters did depend on C 4:0 n (linear) in the OW group (Table 4). Additionally, the C5:0 $\mathrm{n}$ (linear) levels were related to the week of pregnancy, altered glucose levels at $0 \mathrm{~min}$ in the OGTT, and glycated hemoglobin (Table 4).

Table 3. Analysis of the relationship between SCFAs in the stool and the overall parameters in the groups of pregnant women.

\begin{tabular}{|c|c|c|c|c|c|c|c|c|}
\hline Parameters & C 2:0 & C 3:0 & $\begin{array}{c}\mathrm{C} 4: 0 \mathrm{i} \\
\text { (Branched) }\end{array}$ & $\begin{array}{c}\text { C 4:0 n } \\
\text { (Linear) }\end{array}$ & $\begin{array}{c}\text { C 5:0 i } \\
\text { (Branched) }\end{array}$ & $\begin{array}{c}\text { C 5:0 n } \\
\text { (Linear) }\end{array}$ & $\begin{array}{c}\text { C 6:0 i } \\
\text { (Branched) }\end{array}$ & $\begin{array}{c}\text { C 6:0n } \\
\text { (Linear) }\end{array}$ \\
\hline Week of pregnancy & 0.034 & -0.073 & 0.004 & 0.043 & 0.027 & -0.035 & 0.235 & -0.118 \\
\hline Body weight before pregnancy (kg) & -0.026 & 0.115 & 0.045 & 0.073 & 0.010 & -0.124 & 0.180 & -0.333 \\
\hline BMI before pregnancy & 0.080 & 0.007 & -0.024 & 0.106 & -0.044 & -0.192 & 0.177 & -0.369 \\
\hline Body weight during pregnancy (kg) & -0.022 & 0.102 & 0.025 & 0.094 & 0.004 & -0.133 & 0.204 & -0.353 \\
\hline BMI during pregnancy & 0.095 & -0.013 & -0.047 & 0.127 & -0.052 & -0.207 & 0.208 & -0.398 \\
\hline Insulin $(\mathrm{mU} / \mathrm{mL})$ & 0.342 & 0.000 & -0.147 & -0.088 & -0.085 & -0.246 & 0.261 & -0.455 \\
\hline HbA1c (\%) & -0.247 & 0.443 & 0.185 & -0.236 & 0.266 & 0.228 & -0.085 & -0.147 \\
\hline Fasting glucose (mg/dL) & -0.072 & 0.473 & 0.172 & -0.420 & 0.271 & 0.205 & 0.296 & -0.260 \\
\hline OGTT at $60 \mathrm{~min}(\mathrm{mg} / \mathrm{dL})$ & 0.013 & -0.187 & -0.367 & 0.290 & -0.252 & -0.066 & -0.122 & 0.238 \\
\hline OGTT at $120 \mathrm{~min}(\mathrm{mg} / \mathrm{dL})$ & 0.023 & 0.193 & -0.021 & -0.310 & 0.099 & 0.140 & 0.243 & 0.155 \\
\hline
\end{tabular}

Table 4. Analysis of the relationship between SCFA in the stool and the parameters in the group of overweight and obese pregnant women (OW).

\begin{tabular}{ccccccccc}
\hline Parameters & C 2:0 & C 3:0 & $\begin{array}{c}\text { C 4:0 i } \\
\text { (Branched) }\end{array}$ & $\begin{array}{c}\text { C 4:0 } \mathbf{n} \\
\text { (Linear) }\end{array}$ & $\begin{array}{c}\text { C 5:0 i } \\
\text { (Branched) }\end{array}$ & $\begin{array}{c}\text { C 5:0 n } \\
\text { (Linear) }\end{array}$ & $\begin{array}{c}\text { C 6:0 i } \\
\text { (Branched) }\end{array}$ & $\begin{array}{c}\text { C 6:0 } \mathbf{n} \\
\text { (Linear) }\end{array}$ \\
\hline Week of pregnancy & 0.233 & 0.387 & 0.421 & 0.215 & 0.515 & $\mathbf{0 . 5 9 7}$ & 0.011 & -0.095 \\
\hline Body weight before pregnancy $(\mathrm{kg})$ & $\mathbf{0 . 6 5 1}$ & 0.539 & 0.009 & $\mathbf{0 . 6 4 1}$ & 0.137 & 0.214 & -0.342 & -0.176 \\
\hline BMI before pregnancy & $\mathbf{0 . 7 2 8}$ & 0.405 & -0.114 & $\mathbf{0 . 6 9 0}$ & 0.036 & 0.119 & -0.340 & -0.213 \\
\hline Body weight during pregnancy $(\mathrm{kg})$ & $\mathbf{0 . 6 4 9}$ & $\mathbf{0 . 5 6 5}$ & 0.035 & $\mathbf{0 . 6 5 8}$ & 0.179 & 0.277 & -0.363 & -0.142 \\
\hline BMI during pregnancy & $\mathbf{0 . 7 2 9}$ & 0.430 & -0.088 & $\mathbf{0 . 7 0 7}$ & 0.080 & 0.185 & -0.360 & -0.180 \\
\hline Body weight gain $(\mathrm{kg})$ & -0.364 & -0.057 & 0.187 & -0.105 & 0.251 & 0.366 & -0.046 & 0.334 \\
\hline Insulin $(\mathrm{mU} / \mathrm{mL})$ & $\mathbf{0 . 6 5 4}$ & 0.011 & -0.508 & 0.378 & -0.353 & -0.217 & -0.233 & -0.185 \\
\hline HbA1c $(\%)$ & $\mathbf{0 . 6 8 6}$ & $\mathbf{0 . 6 7 8}$ & 0.147 & 0.484 & 0.355 & $\mathbf{0 . 5 6 2}$ & -0.353 & 0.055 \\
\hline Fasting glucose $(\mathrm{mg} / \mathrm{dL})$ & $\mathbf{0 . 6 1 5}$ & $\mathbf{0 . 7 7 4}$ & 0.226 & 0.339 & 0.434 & $\mathbf{0 . 5 5 9}$ & -0.242 & -0.118 \\
\hline OGTT at $60 \mathrm{~min}(\mathrm{mg} / \mathrm{dL})$ & $\mathbf{0 . 5 7 3}$ & 0.527 & -0.084 & 0.510 & 0.150 & 0.406 & -0.413 & -0.042 \\
\hline OGTT at $120 \mathrm{~min}(\mathrm{mg} / \mathrm{dL})$ & 0.347 & $\mathbf{0 . 5 9 2}$ & 0.210 & -0.143 & 0.401 & 0.423 & 0.129 & -0.102 \\
\hline
\end{tabular}

Bold text-significant.

Table 5. Analysis of the relationship between SCFAs in the stool, anthropometric parameters, and the carbohydrate metabolism parameters in the control group (CG).

\begin{tabular}{ccccccccc}
\hline Parameter & C 2:0 & C 3:0 & $\begin{array}{c}\text { C 4:0 i } \\
\text { (Branched) }\end{array}$ & $\begin{array}{c}\text { C 4:0 n } \\
\text { (Linear) }\end{array}$ & $\begin{array}{c}\text { C 5:0 i } \\
\text { (Branched) }\end{array}$ & $\begin{array}{c}\text { C 5:0 n } \\
\text { (Linear) }\end{array}$ & $\begin{array}{c}\text { C 6:0 i } \\
\text { (Branched) }\end{array}$ & $\begin{array}{c}\text { C 6:0 n } \\
\text { (Linear) }\end{array}$ \\
\hline Week of gestation & 0.609 & 0.296 & 0.038 & 0.467 & -0.099 & -0.201 & 0.480 & -0.128 \\
\hline Body weight before pregnancy $(\mathrm{kg})$ & $\mathbf{0 . 9 1 3}$ & $\mathbf{0 . 8 4 6}$ & 0.608 & $\mathbf{0 . 7 0 4}$ & 0.412 & 0.611 & 0.159 & 0.045 \\
\hline BMI before pregnancy & $\mathbf{0 . 8 6 5}$ & $\mathbf{0 . 8 7 0}$ & 0.631 & 0.628 & 0.463 & 0.612 & 0.176 & -0.018 \\
\hline Body weight during pregnancy $(\mathrm{kg})$ & $\mathbf{0 . 9 4 9}$ & $\mathbf{0 . 7 9 6}$ & 0.525 & $\mathbf{0 . 7 2 1}$ & 0.327 & 0.464 & 0.289 & -0.015 \\
\hline BMI during pregnancy & $\mathbf{0 . 9 2 7}$ & $\mathbf{0 . 8 3 6}$ & 0.565 & $\mathbf{0 . 6 6 7}$ & 0.390 & 0.483 & 0.320 & -0.076 \\
\hline Body weight gain $(\mathrm{kg})$ & -0.085 & -0.436 & -0.480 & -0.194 & -0.422 & $-\mathbf{0 . 7 1 6}$ & 0.518 & -0.275 \\
\hline Insulin $(\mathrm{mU} / \mathrm{mL})$ & -0.313 & -0.230 & -0.079 & $\mathbf{- 0 . 6 6 9}$ & 0.140 & -0.282 & 0.629 & -0.503 \\
\hline HbA1c $(\%)$ & $\mathbf{0 . 8 9 8}$ & $\mathbf{0 . 8 8 8}$ & 0.628 & $\mathbf{0 . 7 4 8}$ & 0.425 & 0.582 & 0.139 & 0.009 \\
\hline Fasting glucose $(\mathrm{mg} / \mathrm{dL})$ & $\mathbf{0 . 9 2 7}$ & $\mathbf{0 . 8 1 1}$ & 0.519 & $\mathbf{0 . 6 6 1}$ & 0.343 & 0.543 & 0.271 & 0.055 \\
\hline OGTT at $60 \mathrm{~min}(\mathrm{mg} / \mathrm{dL})$ & $\mathbf{0 . 7 3 0}$ & 0.470 & 0.252 & $\mathbf{0 . 8 1 1}$ & 0.094 & 0.371 & 0.240 & 0.331 \\
\hline OGTT at 120 min $(\mathrm{mg} / \mathrm{dL})$ & $\mathbf{0 . 7 8 1}$ & 0.536 & 0.270 & $\mathbf{0 . 8 1 6}$ & 0.090 & 0.417 & 0.181 & 0.362 \\
\hline
\end{tabular}


A similar relationship with the parameters of carbohydrate metabolism was found in the group of women with normal body weight (Table 5). C2:0, C3:0, and C4:0n (linear) showed a correlation with anthropometric measurements. Moreover, C2:0, C3:0, branched, and C4:0n (linear) were correlated with the parameters of carbohydrate metabolism. Negative correlations of C4:0n and C5:0n (linear) with insulin levels and body weight gain, respectively, were observed (Table 5).

\section{Discussion}

A correlation between the SCFA produced by the anaerobic fermentation of carbohydrates in the colon and the parameters related to the metabolism of pregnant women and their anthropometric parameters was observed. At the same time, no major differences in nutrient and dietary fiber intake were found. Therefore, it should be concluded that the levels of SCFAs were mainly associated with the gut microbiota in the studied patients although there was a noticeable trend of lower fiber and higher glucose consumption in the group of obese women. Both nutrients are essential for the development of dysbiosis and the production of SCFAs [31]. In the research of Rahat-Rozenbloom et al., the investigators analyzed the effects of SCFAs on carbohydrate metabolism. It has been proven that the increase in colonic propionate stimulates both the insulin secretion in $\beta$-cells and glucagon-like peptide 1 (GLP-1) activity. In addition, propionate, with long-term action, protects $\beta$-cells from apoptosis induced by pro-inflammatory cytokines and free fatty acid (FFA) activity [32]. Moreover, a longer period of propionate production was also associated with faster elevation of the plasma insulin concentration, $30 \mathrm{~min}$ after a meal. SCFAs transmit signals in such a way that they bind to the free fatty acid receptors 2 and 3 (FFAR2 and FFAR3). Propionate has been found to stimulate insulin secretion in pancreatic cells via FFAR2. Higher FFAR2 activity was detected in the endocrine pancreas compared to its exocrine portion. According to the research studies, the stimulating effect of propionate on insulin secretion in human pancreatic islets depends on the protein kinase $\mathrm{C}(\mathrm{PKC})$ activation. C3:0 acid has also the ability to participate in the tricarboxylic acid (TCA) cycle. Thus, it can secrete larger amounts of insulin by increasing the synthesis of adenosine triphosphate (ATP) [18]. In our study, no such effect could be observed.

It has been demonstrated in animal models that a high-cholesterol diet is associated with significant changes in SCFA levels by affecting butyrate and propionate production and an increase in LPS secretion $[32,33]$. However, in our own studies, cholesterol consumption did not differ significantly between the groups. In our research, an increase in propionate concentration was observed in the group of obese women compared to the control group, which could be a confirmation of one possible cause of increased insulin levels occurring in the later weeks of pregnancy. However, due to the statistically insignificant differences between the groups, no relationship between C3:0 acid and insulin concentrations was found, although an association with blood glucose level at 0,120 min for OGTT and glycated hemoglobin was observed.

It seems that obese women before pregnancy are more likely to suffer from pathological disturbances associated with intestinal permeability, possibly caused by intestinal dysbiosis [33,34]. Moreover, C5:0 acid, which decreased in the group of obese women before pregnancy, is also a good marker of liver fat accumulation and may predict the occurrence of type 2 diabetes [35].

Generally, in the group of pregnant women, the most significant relationships were found for C3:0, C4:0 $\mathrm{n}$, and C6:0n acids, where the linear acids had a negative correlation. A positive correlation between C3:0, glycated hemoglobin, and fasting glucose levels confirmed the findings of other researchers, suggesting that propionate could set the precedent for the treatment of obesity $[17,26]$. Propionate may play a significant role in obesity, where non-esterified fatty acids (NEFAs) and pro-inflammatory cytokines trigger pancreatic $\beta$-cell dysfunction and apoptosis [29]. The increase in propionic acid levels with obesity and the correlation with glycosylated hemoglobin and fasting glucose levels in our research should be considered a probable factor of glucose metabolism disorders in pregnant women.

Following these lines of deductive reasoning, the C6:0 (linear) acids appear to be negatively related to the insulin level. Due to the lower rate of C6:0 (linear) acid in the total SCFA pool, it might be 
worthwhile to use this organic compound for management of excessive weight gain, but no relevant literature has been found on this subject.

However, it has been proven that GDM diagnosed in the later stages of pregnancy is associated with an inappropriate composition of the microbiota at the time of diagnosis [5]. The growth of Bifidobacteria correlates with increased glucose tolerance, regulates IO and insulin secretion, and helps reduce inflammation. SCFAs influence glycemia through glucagon-like peptide 1 (GLP-1) and pancreatic polypeptide (PPY), which are intestinal hormones. The intestinal hormone PYY is a peptide that acts as a paracrine substance to stimulate the feelings of satiety or hunger in the control center. In addition, it stimulates the action of insulin in muscles and adipose tissue. In a study in which colonocytes were collected from the colon of humans and rats, FFAR2 and FFAR3 receptors were linked to PYY-secreting L cells. In an animal model, after intracolonic SCFA infusions, an increase in the body's PYY level was observed [10]. In diabetes, an increased level of tissue plasminogen activator inhibitor-1 (PAI-1) is also observed, which correlates with hypertension and microbiota composition responsible for butyrate production as well. Women diagnosed with GDM had higher arterial blood pressure values [3].

The group of bacteria to which microorganisms of the genera Streptococcus, Bifidobacterium, Escherichia and Lactobacillus belong affects the synthesis of neurotransmitters in the nervous system. Their imbalance may contribute to increased vessel tension, their narrowing, increased peripheral resistance, and subsequently to arterial hypertension development [36]. Moreover, the role of butyrate and the enzyme butyrate kinase by intensifying the action of PAI- 1 in the prevention of the development of arterial hypertension during pregnancy is emphasized by other investigators [36]. The number of bacteria responsible for butyrate production and the number of copies of the butyrate kinase enzyme are inversely correlated with systolic and diastolic blood pressure and PAI-1, the marker of inflammation in women who are overweight and obese during pregnancy [3]. It is reported that taking probiotics is helpful in lowering blood pressure [37]. Taking into consideration the fact that acetate constitutes the main SCFA pool (about 37\%), correlations of this acid concentration between the pre-pregnancy obese and normal-weight women groups were checked. We demonstrated an influence of acetate on anthropometric parameters in both groups of women. However, the composition of the gut microbiota has not been studied, which is a limitation of the study.

Thus, acids may be the first component elements of the conceptual puzzle changing the pathways of carbohydrate metabolism, focused on the mechanisms associated with the accumulation of reserves in order to survive, the disturbance of which destroys one of the first homeostasis barriers in the body.

Research studies on preeclampsia (PE), which is related to the immune system, suggest a significant reduction in the level of acetate in the blood serum of pregnant women [38]. We observed such a correlation, especially in the group of obese women who were more likely to develop PE before pregnancy. In a study on germ-free mice, as much as a $30 \%$ increase in acetate contributed to reducing the risk of PE. In addition, acetate is an important factor influencing blood pressure regulation, a disorder of which leads to PE clinical features [39].

An interesting observation coming from our research is the fact that linear SCFAs participate in the regulation of carbohydrate metabolism regardless of obesity. Dietary fiber-related SCFAs are involved in the regulation of carbohydrate metabolism, while BSCFAs, isobutyric, isovaleric, and isocaproic acid, from fermentation of undigested protein reaching the colon, do not have such an effect.

\section{Materials and Methods}

\subsection{Study Group}

The study was approved by the Ethical Committee of Pomeranian Medical University (approval code: KB-0012-69-18; approval date: 18/06/2018), and informed consent was obtained from all individual participants included in the study. The study group consisted of 90 Caucasian women, mean age $32.17 \pm 5.32$ years. The diagnosis of pregnancy was confirmed based on sensitive biochemical assays and high-resolution ultrasonography (General Electric, Voluson E8 Expert, 2015) 
and women from the 10th week of gestation were included in the study. The exclusion criteria were twin pregnancies, refusal of consent for examination, the presence of active infection or neoplastic disease. The characteristics of the study group are presented below in Table 6 .

Table 6. Characteristics of the study group of women $(n=90)$.

\begin{tabular}{ccc}
\hline Parameter & Avg & SD \\
\hline Age (years) & 32.17 & 5.32 \\
\hline Height $(\mathrm{m})$ & 1.68 & 0.05 \\
\hline Body weight before pregnancy $(\mathrm{kg})$ & 85.19 & 20.69 \\
\hline Body weight during pregnancy $(\mathrm{kg})$ & 89.64 & 19.73 \\
\hline BMI before pregnancy $\left(\mathrm{kg} / \mathrm{m}^{2}\right)$ & 29.42 & 8.45 \\
\hline BMI during pregnancy $\left(\mathrm{kg} / \mathrm{m}^{2}\right)$ & 31.36 & 7.53 \\
\hline Week of gestation $(\mathrm{week})$ & 20.64 & 7.73 \\
\hline Fasting insulin $(\mathrm{mU} / \mathrm{mL})$ & 15.79 & 14.02 \\
\hline HbA1 $(\%)$ & 5.11 & 0.32 \\
\hline Fasting glucose $(\mathrm{mg} / \mathrm{dL})$ & 89.46 & 11.82 \\
\hline OGTT at 60 min $(\mathrm{mg} / \mathrm{dL})$ & 134.78 & 28.33 \\
\hline OGTT at 120 min $(\mathrm{mg} / \mathrm{dL})$ & 114.52 & 29.59 \\
\hline
\end{tabular}

In order to eliminate the influence of the obesity-associated chronic states and to analyze the impact of pregnancy on the SCFA levels, the study group was divided into obese patients and patients with normal BMI before pregnancy. The first group consisted of 48 women who had an overweight and obese pre-pregnancy BMI over $30(\mathrm{OW})$; the second group, the control group (CG), consisted of 42 women with normal body weight, as shown in Table 7.

Table 7. Division of the study group of women.

\begin{tabular}{cccc}
\hline Parameter & OW Avg \pm SD & CG Avg \pm SD & $p$-Value \\
\hline Age $($ years $)$ & $30.26 \pm 5.21$ & $32.34 \pm 5.14$ & NS \\
\hline Height $(\mathrm{m})$ & $1.68 \pm 0.06$ & $1.67 \pm 0.05$ & NS \\
\hline Body weight before pregnancy $(\mathrm{kg})$ & $100.11 \pm 19.17$ & $66.93 \pm 13.98$ & $0.0000004^{*}$ \\
\hline Body weight during pregnancy $(\mathrm{kg})$ & $102.42 \pm 20.01$ & $72.29 \pm 15.05$ & $0.0001^{*}$ \\
\hline BMI before pregnancy $\left(\mathrm{kg} / \mathrm{m}^{2}\right)$ & $34.44 \pm 8.52$ & $22.72 \pm 6.62$ & $0.00001^{*}$ \\
\hline BMI during pregnancy $\left(\mathrm{kg} / \mathrm{m}^{2}\right)$ & $35.21 \pm 8.78$ & $25.17 \pm 6.18$ & $0.012^{*}$ \\
\hline Weight gain $(\mathrm{kg})$ & $2.33 \pm 4.21$ & $7.23 \pm 9.67$ & 0.004 \\
\hline Week of gestation $(\mathrm{week})$ & $19.93 \pm 6.49$ & $21.82 \pm 7.13$ & $\mathrm{NS}$ \\
\hline Fasting insulin $(\mathrm{mU} / \mathrm{mL})$ & $16.31 \pm 8.08$ & $12.77 \pm 10.82$ & $\mathrm{NS}$ \\
\hline HbA1 $(\%)$ & $5.06 \pm 0.84$ & $4.88 \pm 0.83$ & $\mathrm{NS}$ \\
\hline Fasting glucose $(\mathrm{mg} / \mathrm{dL})$ & $92.36 \pm 20.57$ & $82.91 \pm 11.01$ & $\mathrm{NS}$ \\
\hline OGTT at 60 min $(\mathrm{mg} / \mathrm{dL})$ & $136.01 \pm 29.22$ & $126.51 \pm 27.03$ & $\mathrm{NS}$ \\
\hline OGTT at 120 min $(\mathrm{mg} / \mathrm{dL})$ & $117.59 \pm 34.17$ & $114.43 \pm 23.99$ & $\mathrm{NS}$ \\
\hline
\end{tabular}

A 24-h consumption interview was conducted twice. The interviews were done two days before collecting a stool sample. To provide information regarding the size of the consumed meals, an album of products and meal photos was used. The menus were analyzed using quantitative 
methods. The Dieta 6D program, recommended by the National Centre of Nutritional Education (Warsaw, Poland), was used. The acquired data were compared between groups.

\subsection{Sampling}

\subsubsection{The Blood Chemistry Parameters}

The blood samples (approximately $5 \mathrm{~mL}$ ) were taken from a vein in the arm in the morning strictly on an empty stomach after a 10-12-h break in meals. Biochemical parameters of carbohydrate metabolism (glucose, insulin, glycosylated hemoglobin) were performed using standard laboratory methods in an accredited hospital laboratory using the Roche Diagnostic Cobas e411 and Cobas Integra B Plus analyses. An oral glucose tolerance test (OGTT) was performed on women who had a fasting glucose level in blood below $100 \mathrm{mg} / \mathrm{dL}$ and consented; $75 \mathrm{~g}$ of glucose was administered to drink and its level was measured after 60 and $120 \mathrm{~min}$ (Table 2). No women took metformin or insulin. The obese group (OW) consisted of 20 patients (normal glucose tolerant $(n=11)$, impaired glucose tolerance $(n=3)$, impaired fasting glucose $(n=1)$, and impaired fasting glucose + impaired glucose tolerance $(n=5))$, and the control group (CG) consisted of 15 normal glucose-tolerant patients.

\subsubsection{Collecting a Stool Sample}

All study participants were asked to collect a stool sample into a screw-capped collection container and demanded not to use laxatives and change the diet. Women sampled feces after overnight fasting, to establish a common reference point for food intake, and delivered these to the office within $24 \mathrm{~h}$ (a factor determining SCFA synthesis). After the stool collection, the samples were immediately frozen at $-20^{\circ} \mathrm{C}$ and transported on ice to our laboratory, then stored at $-80^{\circ} \mathrm{C}$ until the analyses. We carried out the analysis within six months after the fecal sample collection [40].

\subsection{Isolation of SCFAs}

A $0.5 \mathrm{~g}$ fecal sample was suspended in a tube containing $5 \mathrm{~mL}$ of distilled water and mixed intensively for $5 \mathrm{~min}$ by used shaker. Using $5 \mathrm{M} \mathrm{HCl}$ solution, the $\mathrm{pH}$ of suspension was adjusted to 2-3. The samples were then shaken for $10 \mathrm{~min}$ and centrifuged for $20 \mathrm{~min}$ at $5000 \mathrm{rpm}$. Subsequently, the supernatant was filtered (Ø $400 \mu \mathrm{m}$ filter) and transferred to a chromatographic vial for gas chromatography analyses [40].

\subsection{Gas Chromatography SCFAs}

The following SCFAs were analyzed: acetic acid (C 2:0), propionic acid (C 3:0), isobutyric acid (C 4:0 i), butyric acid (C 4:0 n), isovaleric acid (C 5:0 i) valeric acid (C 5:0 n), isocaproic acid (C 6:0 i), caproic acid (C 6:0 n). Chromatographic analyses were carried out using the Agilent Technologies 1260 A GC system with a flame ionization detector (FID). A fused-silica capillary column with a free fatty acid phase (DB-FFAP, $30 \mathrm{~m} \times 0.53 \mathrm{~mm} \times 0.5 \mathrm{um}$ ) was used. The carrier gas was hydrogen at a flow rate equal to $14.4 \mathrm{~mL} / \mathrm{min}$. The initial temperature $\left(100^{\circ} \mathrm{C}\right)$ was maintained for $0.5 \mathrm{~min}$, then raised to $180^{\circ} \mathrm{C}$ with ramping of $8^{\circ} \mathrm{C} / \mathrm{min}$ to be constant for $1 \mathrm{~min}$. Subsequently, the temperature was increased to $200{ }^{\circ} \mathrm{C}$ (ramping $20^{\circ} \mathrm{C} / \mathrm{min}$ ), to finally reach $200{ }^{\circ} \mathrm{C}$ and then sustained for $5 \mathrm{~min}$. The injection volume was $1 \mu \mathrm{L}$ and the run time of a single analysis was $17.5 \mathrm{~min}$. Fatty acids were identified by comparing their retention times with those of commercially available standards [41].

\subsection{Statistical Analyses}

Statistical analyses were performed with Statistica 13.3 software (Statsoft, Cracow, Poland). The Shapiro-Wilk parametric test was used (the distribution in most cases was normal). A non-parametric test was used: Mann-Whitney test for comparisons between groups (obese women before pregnancy and control group); $p<0.05$ was considered statistically significant. Then, 
we correlated the SCFA percentage and the biochemical parameters of carbohydrate metabolism and anthropometric measurements in women.

\section{Conclusions}

In conclusion, we report that SCFAs may at least partially contribute in the course of pregnancy and participate in the alteration of carbohydrate metabolism. The influence of acetic acid during pregnancy on some anthropometric parameters was visible in both groups. Linear butyrate, valeric and especially propionate regulate glucose metabolism by stimulating the process of intestinal gluconeogenesis. The level of propionic acid decreases with the course of pregnancy, while its increase is characteristic of obese women, which is associated with many metabolic adaptations. Linear caproic acid and propionic acid levels can be an important critical point in maintaining lower anthropometric parameters during pregnancy.

Author Contributions: Conceptualization, M.S. and M.Z.; methodology, M.S., J.K., D.M. and M.Z.; software, D.K., M.S.; validation, M.S., Z.C. and M.Z.; formal analysis, M.S., J.K., D.M., M.Z.; investigation, M.S., M.Z.; resources, M.S., Z.C., M.Z.; data curation, M.S., J.K., Z.C., M.Z.; writing-original draft preparation, M.S., M.Z.; writing-review and editing, D.K., M.S., M.Z.; visualization, M.S., M.Z.; supervision, M.S., M.Z.; project administration, M.S. and M.Z.; funding acquisition, M.S. and M.Z. All authors have read and agreed to the published version of the manuscript.

Funding: The project is financed by the program of the Pomeranian Medical University in Szczecin, Poland, under the name Stimulation Science Fund number FSN-330-07/19.

Conflicts of Interest: All authors declare no conflict of interest.

\section{References}

1. Sender, R.; Fuchs, S.; Milo, R. Revised Estimates for the Number of Human and Bacteria Cells in the Body. PLoS Biol. 2016, 14, e1002533. [CrossRef]

2. Bamberger, C.; Rossmeier, A.; Lechner, K.; Wu, L.; Waldmann, E.; Fischer, S.; Stark, R.G.; Altenhofer, J.; Henze, K.; Parhofer, K.G. A Walnut-Enriched Diet Affects Gut Microbiome in Healthy Caucasian Subjects: A Randomized, Controlled Trial. Nutrients 2018, 10, 244. [CrossRef]

3. Gomez-Arango, L.F.; Barrett, H.L.; Simmons, D.; Callaway, L.; Morrison, M.; Nitert, M.D. Increased Systolic and Diastolic Blood Pressure Is Associated with Altered Gut Microbiota Composition and Butyrate Production in Early Pregnancy. Hypertension 2016, 68, 974-981. [CrossRef] [PubMed]

4. Rooks, M.G.; Garrett, W.S. Gut microbiota, metabolites and host immunity. Nat. Rev. Immunol. 2016, 16, 341-352. [CrossRef] [PubMed]

5. Gill, P.A.; Van Zelm, M.C.; Muir, J.G.; Gibson, P.R. Review article: Short chain fatty acids as potential therapeutic agents in human gastrointestinal and inflammatory disorders. Aliment. Pharmacol. Ther. 2018, 48, 15-34. [CrossRef]

6. Voltolini, C.; Battersby, S.; Etherington, S.L.; Petraglia, F.; Norman, J.E.; Jabbour, H.N. A Novel Antiinflammatory Role for the Short-Chain Fatty Acids in Human Labor. Endocrinology 2012, 153, 395-403. [CrossRef] [PubMed]

7. Gao, Z.; Yin, J.; Zhang, J.; Ward, R.E.; Martin, R.J.; Lefevre, M.; Cefalu, W.T.; Ye, J. Butyrate Improves Insulin Sensitivity and Increases Energy Expenditure in Mice. Diabetes 2009, 58, 1509-1517. [CrossRef]

8. Heimann, E.; Nyman, M.; Pålbrink, A.-K.; Lindkvist-Petersson, K.; Degerman, E. Branched short-chain fatty acids modulate glucose and lipid metabolism in primary adipocytes. Adipocyte 2016, 5, 359-368. [CrossRef]

9. Sakata, T. Pitfalls in short-chain fatty acid research: A methodological review. Anim. Sci. J. 2019, 90, 3-13. [CrossRef]

10. Besten, G.D.; Van Eunen, K.; Groen, A.K.; Venema, K.; Reijngoud, D.-J.; Bakker, B.M. The role of short-chain fatty acids in the interplay between diet, gut microbiota, and host energy metabolism. J. Lipid Res. 2013, 54, 2325-2340. [CrossRef]

11. Kuczyńska, B.; Wasilewska, A.; Biczysko, M.; Banasiewicz, T.; Drews, M. Krótkołańcuchowe kwasy tłuszczowe-mechanizmy działania, potencjalne zastosowania kliniczne oraz zalecenia dietetyczne. Now. Lek. 2011, 80, 299-304. 
12. Walker, A.W.; Duncan, S.H.; Leitch, E.C.M.; Child, M.W.; Flint, H.J. pH and Peptide Supply Can Radically Alter Bacterial Populations and Short-Chain Fatty Acid Ratios within Microbial Communities from the Human Colon. Appl. Environ. Microbiol. 2005, 71, 3692-3700. [CrossRef]

13. Czajkowska, A.; Szponar, B. Krótkołańcuchowe kwasy tłuszczowe (SCFA) jako produkty metabolizmu bakterii jelitowych oraz ich znaczenie dla organizmu gospodarza. Postepy Hig. Med. Dosw. 2018, 72, 131-142. [CrossRef]

14. Topping, D.L.; Clifton, P.M. Short-Chain Fatty Acids and Human Colonic Function: Roles of Resistant Starch and Nonstarch Polysaccharides. Physiol. Rev. 2001, 81, 1031-1064. [CrossRef]

15. Lv, Y.; Yan, Z.; Zhao, X.; Gang, X.; He, G.; Sun, L.; Li, Z.; Wang, G. The effects of gut microbiota on metabolic outcomes in pregnant women and their offspring. Food Funct. 2018, 9, 4537-4547. [CrossRef]

16. Walker, W.A.; Iyengar, R.S. Breast milk, microbiota, and intestinal immune homeostasis. Pediatr. Res. 2015, 77, 220-228. [CrossRef]

17. Edwards, S.M.; Cunningham, S.A.; Dunlop, A.L.; Corwin, E.J. The Maternal Gut Microbiome During Pregnancy. MCN Am. J. Matern. Nurs. 2017, 42, 310-317. [CrossRef]

18. Pingitore, A.; Chambers, E.S.; Hill, T.; Maldonado, I.R.; Liu, B.; Bewick, G.; Morrison, D.J.; Preston, T.; Wallis, G.A.; Tedford, C.; et al. The diet-derived short chain fatty acid propionate improves beta-cell function in humans and stimulates insulin secretion from human islets in vitro. Diabetes Obes. Metab. 2016, 19, 257-265. [CrossRef]

19. Venegas, D.P.; De La Fuente, M.K.; Landskron, G.; González, M.J.; Quera, R.; Dijkstra, G.; Harmsen, H.J.M.; Faber, K.N.; Hermoso, M.A. Short Chain Fatty Acids (SCFAs)-Mediated Gut Epithelial and Immune Regulation and Its Relevance for Inflammatory Bowel Diseases. Front. Immunol. 2019, 10, 277. [CrossRef]

20. Mei, C.; Yang, W.; Wei, X.; Wu, K.; Huang, D. The Unique Microbiome and Innate Immunity During Pregnancy. Front. Immunol. 2019, 10. [CrossRef]

21. Fuhler, G.M. The immune system and microbiome in pregnancy. Best Pract. Res. Clin. Gastroenterol. 2020, 101671. [CrossRef]

22. Mor, G.; Aldo, P.; Alvero, A.B. The unique immunological and microbial aspects of pregnancy. Nat. Rev. Immunol. 2017, 17, 469-482. [CrossRef]

23. DiGiulio, D.B.; Callahan, B.J.; McMurdie, P.J.; Costello, E.K.; Lyell, D.J.; Robaczewska, A.; Sun, C.L.; Goltsman, D.S.A.; Wong, R.J.; Shaw, G.; et al. Temporal and spatial variation of the human microbiota during pregnancy. Proc. Natl. Acad. Sci. USA 2015, 112, 11060-11065. [CrossRef]

24. Taddei, C.R.; Cortez, R.V.; Mattar, R.; Torloni, M.R.; Daher, S. Microbiome in normal and pathological pregnancies: A literature overview. Am. J. Reprod. Immunol. 2018, 80, e12993. [CrossRef]

25. Koren, O.; Goodrich, J.K.; Cullender, T.C.; Spor, A.; Laitinen, K.; Bäckhed, H.K.; Gonzalez, A.; Werner, J.J.; Angenent, L.T.; Knight, R.; et al. Host Remodeling of the Gut Microbiome and Metabolic Changes during Pregnancy. Cell 2012, 150, 470-480. [CrossRef]

26. Priyadarshini, M.; Thomas, A.; Reisetter, A.C.; Scholtens, D.M.; Wolever, T.M.S.; Josefson, J.L.; Layden, B.T. Maternal short-chain fatty acids are associated with metabolic parameters in mothers and newborns. Transl. Res. 2014, 164, 153-157. [CrossRef]

27. Gomez-Arango, L.F.; Barrett, H.L.; Wilkinson, S.A.; Callaway, L.; McIntyre, H.D.; Morrison, M.; Nitert, M.D. Low dietary fiber intake increases Collinsella abundance in the gut microbiota of overweight and obese pregnant women. Gut Microbes 2018, 9, 189-201. [CrossRef]

28. Vinolo, M.A.R.; Rodrigues, H.G.; Hatanaka, E.; Sato, F.T.; Sampaio, S.C.; Curi, R. Suppressive effect of short-chain fatty acids on production of proinflammatory mediators by neutrophils. J. Nutr. Biochem. 2011, 22, 849-855. [CrossRef]

29. Röytiö, H.; Mokkala, K.; Vahlberg, T.; Laitinen, K. Dietary intake of fat and fibre according to reference values relates to higher gut microbiota richness in overweight pregnant women. Br. J. Nutr. 2017, 118, 343-352. [CrossRef]

30. Tan, J.; McKenzie, C.; Potamitis, M.; Thorburn, A.N.; Mackay, C.R.; Macia, L. The Role of Short-Chain Fatty Acids in Health and Disease. Adv. Immunol. 2014, 121, 91-119. [CrossRef]

31. Ojo, O.; Feng, Q.-Q.; Ojo, O.O.; Wang, X.-H. The Role of Dietary Fibre in Modulating Gut Microbiota Dysbiosis in Patients with Type 2 Diabetes: A Systematic Review and Meta-Analysis of Randomised Controlled Trials. Nutrients 2020, 12, 3239. [CrossRef] 
32. Rahat-Rozenbloom, S.; Fernandes, J.; Cheng, J.; Wolever, T.M. Acute increases in serum colonic short-chain fatty acids elicited by inulin do not increase GLP-1 or PYY responses but may reduce ghrelin in lean and overweight humans. Eur. J. Clin. Nutr. 2017, 71, 953-958. [CrossRef]

33. Nagpal, R.; Newman, T.M.; Wang, S.; Jain, S.; Lovato, J.F.; Yadav, H. Obesity-Linked Gut Microbiome Dysbiosis Associated with Derangements in Gut Permeability and Intestinal Cellular Homeostasis Independent of Diet. J. Diabetes Res. 2018, 2018, 1-9. [CrossRef] [PubMed]

34. Cox, A.J.; West, N.P.; Cripps, A.W. Obesity, inflammation, and the gut microbiota. Lancet Diabetes Endocrinol. 2015, 3, 207-215. [CrossRef]

35. O'Sullivan, J.F.; Morningstar, J.E.; Yang, Q.; Zheng, B.; Gao, Y.; Jeanfavre, S.; Scott, J.; Fernandez, C.; Zheng, H.; O'Connor, S.; et al. Dimethylguanidino valeric acid is a marker of liver fat and predicts diabetes. J. Clin. Investig. 2017, 127, 4394-4402. [CrossRef]

36. Mortensen, F.; Jørgensen, B.; Christiansen, H.; Sloth-Nielsen, J.; Wolff, B.; Hessov, I. Short-Chain Fatty Acid Enemas Stimulate Plasminogen Activator Inhibitor-1 after Abdominal Aortic Graft Surgery. Thromb. Res. 2000, 98, 361-366. [CrossRef]

37. Yang, T.; Santisteban, M.M.; Rodriguez, V.; Vermali, R.; Ahmari, N.; Carvajal, J.M.; Mohamadzadeh, M.; Gong, M.; Qi, Y.; Zubcevic, J.; et al. Gut Dysbiosis Is Linked to Hypertension. Hypertension 2015, 65, 1331-1340. [CrossRef]

38. Thushara, R.M.; Gangadaran, S.; Solati, Z.; Moghadasian, M.H. Cardiovascular benefits of probiotics: A review of experimental and clinical studies. Food Funct. 2016, 7, 632-642. [CrossRef]

39. Hu, M.; the BIS Investigator Group; Eviston, D.; Hsu, P.; Marino, E.; Chidgey, A.; Santner-Nanan, B.; Wong, K.; Richards, J.L.; Yap, Y.A. Decreased maternal serum acetate and impaired fetal thymic and regulatory T cell development in preeclampsia. Nat. Commun. 2019, 10,1-13. [CrossRef]

40. Skonieczna-Żydecka, K.; Grochans, E.; Maciejewska-Markiewicz, D.; Szkup, M.; Schneider-Matyka, D.; Jurczak, A.; Łoniewski, I.; Kaczmarczyk, M.; Marlicz, W.; Czerwińska-Rogowska, M.; et al. Faecal Short Chain Fatty Acids Profile is Changed in Polish Depressive Women. Nutrients 2018, 10, 1939. [CrossRef]

41. Maciejewska-Markiewicz, D.; Skonieczna-Zydecka, K.; Lukomska, A.; Gutowska, I.; Dec, K.; Kupnicka, P.; Palma, J.; Pilutin, A.; Marlicz, W.; Stachowska, E. The short chain fatty acids and lipopolysaccharides status in Sprague-Dawley rats fed with high-fat and high-cholesterol diet. J. Physiol. Pharmacol. Off. J. Pol. Physiol. Soc. 2018, 69, 205-210.

Publisher's Note: MDPI stays neutral with regard to jurisdictional claims in published maps and institutional affiliations.

(C) 2020 by the authors. Licensee MDPI, Basel, Switzerland. This article is an open access article distributed under the terms and conditions of the Creative Commons Attribution (CC BY) license (http://creativecommons.org/licenses/by/4.0/). 